\title{
How Near Will You Hear? A Response to Benadon, "Near-unisons in Afro-Cuban Ensemble Drumming"
}

\author{
PETER MARTENS \\ Texas Tech University
}

\begin{abstract}
Fernando Benadon (2016) shines a strong objective light onto slight but noticeable timing perturbations in Afro-Cuban drumming practice, coining the term nearunisons to describe non-simultaneous attacks that are perceived as such, but that are also perceived to correspond to the same point on an abstract isochronous grid. I speculate that these data uncover an aspect of the music that will most likely be perceived qualitatively rather than quantitatively —an element of style rather than one of structurebut that the quantitative approach taken here is a crucial first step toward the stylistic analysis of genre-specific microtiming that is generally painted over with the broad brushes of participatory discrepancy or groove.
\end{abstract}

Submitted 2016 September 20; accepted 2016 October 1.

KEYWORDS: style guide, template, format, article, Empirical Musicology Review

With this article Fernando Benadon brings a fascinating repertoire into the domain of empirical corpus analysis for the first time. In my view he should be commended for merely engaging in the unquantifiable professional and/or personal relationships that now allow the empirical research community access to this living, non-notated practice, and more so for what he does with it.

\section{THE CONCEPT OF “NEAR-UNISON”}

Benadon carves out a conceptual space between imprecisely timed but mentally quantized attacks that are either sufficiently proximate to be merged into perceived unisons, or that are sufficiently distant in time to be quantized to distinct (sub)divisions of a metric grid. Both are examples of categorical perception, ably demonstrated in single-stream rhythmic contexts by Desain and Honing (2003), who showed that listeners' perception of attacks relative to an isochronous metric grid are very approximate, at times even counterintuitive. In many of their examples, listeners quantized attacks by hundreds of milliseconds to correspond with simple numeric ratios.

Benadon focuses instead on attacks in concurrent rhythmic strata; a composite hearing of these strata presents the interesting perceptual and conceptual phenomena of near-unisons. These attacks are sufficiently distant in time to be noticed as such (the "near" part), but still must resolve, at a conceptual level, to the same point on an abstract metric grid (the "unison" part). Does this present a challenge to, or nuancing of, the concept of categorical perception, a mode of listening that simultaneously recognizes and discounts timing discrepancies?

\section{NEAR-UNISONS IN PITCH TIME}

Despite the many non-isomorphisms between pitch and time (London, 2002), there are some fruitful analogues to consider here. I immediately recall a concept given me by a middle school band director; he claimed to have developed "acoustic calluses" that made him able to tolerate all but the most cataclysmic intonation from his ensembles. When pressed to explain, we determined that he was actually describing an enlarged just-noticeable difference window. Could he, even in this aurally toughened state, still distinguish his $7^{\text {th }}$ graders' (near-)unison pitches from, say, the Dallas Wind Symphony playing the same (much more nearly) unison pitches? Of course, but his discernment would be one of timbre, quality, or style, not of precise frequency. 
Near-unison examples from the pitch realm that are more intentional than a middle school band's pitch spread include ranks of reeds in an accordion, or pipes in an organ, that are consistently mistuned with respect to one another. "Wet" tuned accordions will typically have one rank of reeds tuned up to 4 cents higher than the others; in terms of frequency, this would pair an A at $440 \mathrm{~Hz}$ with an A at $458 \mathrm{~Hz}$, or a middle C at $262 \mathrm{~Hz}$ with one at $272.5 \mathrm{~Hz}$. Similarly, the shimmering effect of composite organ stops, such as many in the Celeste category, are produced by tuning two ranks of pipes anywhere from 1 to $7 \mathrm{~Hz}$ discrepant, with less pitch difference (and thus less rapid beating) at lower frequencies. Like the band director, listeners' judgments to these combinations of sound are qualitative (a warm sound, a rich sound, a full texture) rather than quantitative (that set of reeds is 4 cents sharp!).

Back in the realm of musical time, we have no shortage of offsets that are also often cast as part of style. The Rolling Stones' drummer Charlie Watts is commonly credited with creating the essence of the group's rhythmic feel, combining laconic back-beat snare attacks with metronomically precise kick drum attacks. The near-unisons that I hear between Watts' snare and Keith Richards' (or Mick Taylor's or Ron Woods') guitar attacks are stylistic traits, rising to that status because of their ubiquity across pieces and across time.

It may be that listeners enculturated to rock or Afro-Cuban musical styles have schematic expectations that allow for, or better, that take no explicit notice of, a $40 \mathrm{~ms}$ or even $60 \mathrm{~ms}$ offset. Put another way, 20ms (or even 10ms) is a noticeable offset if one is listening for offsets. Perhaps, for a typical listener, the near-unisons that Benadon carefully catalogues and sensitively analyzes are, like the Rolling Stones, just "how they play," the characteristic feel of a particular ensemble or drumming genre.

But Benadon's near-unisons may be categorically different from the Stones and the pitch-based examples above because of their lack of consistency from attack point to attack point, and I take this as one of the most significant findings of this work. When the temporal offset-and even serial ordering of attacks - between a bell and conga playing the same pattern ebbs and flows across that pattern, we have a dynamic musical parameter, one that is subject to performer manipulation. Presented with this type of temporal flux, it is less likely that listeners will weld the two instruments together perceptually into a single unique timbre, or that they will ignore the discrepancies unknowingly as a component of style.

My mild skepticism regarding the perceptibility of near-unisons, or more accurately regarding an enculturated audience's propensity to notice them, should in no way detract from the fact that Benadon has at the very least identified in high detail a significant stylistic component of his target repertoire. This identification is every bit as valuable as quantifying, say, the (artistically inconsistent) tuning tendencies of Pablo Casals playing Bach 'cello suites. He has given us a baseline from which we can undertake cultureor ensemble-based style analysis. Indeed, what will add additional import to this line of research would be to combine the objective/empirical analysis with ethnographic/qualitative methods. References early in the article to post-session interviews and to the performers' knowledge of the study paradigm are tantalizing, and might shed light on whether near-unisons are participatory discrepancies, conscious artistic decisions, or somewhere in between.

\section{REFERENCES}

Benadon, F. (2016). Near-Unisons in Afro-Cuban Ensemble Drumming. Empirical Musicology Review, 11(2), 187-201. https://doi.org/10.18061/emr.v11i2.4957

Desain, P. \& Honing, H. (2003). The formation of rhythmic categories and metric priming. Perception 32(3), 341-365. https://doi.org/10.1068/p3370

London, J. (2002). Some Non-Isomorphisms between Pitch and Time. Journal of Music Theory 46(1/2), 127-151. https://doi.org/10.1215/00222909-46-1-2-127 